\title{
COMUNICAÇÃO
}

\section{ESTÁ DESAPARECENDO A GLOMERULOPATIA DA ESQUISTOSSOMOSE MANSÔNICA?}

\author{
Emmanuel Isaias de Souza Correia, Reinaldo P. Martinelli e Heonir Rocha
}

\begin{abstract}
As formas severas de esquistossomose mansônica, particularmente a bépatoesplênica, se acompanham de glomerulopatia geralmente manifesta por sindrome nefrótica. Nos últimos 10 anos reduziu-se muito o número de casos observados desta glomerulopatia no Hospital Universitário Prof. Edgard Santos, um hospital geral num estado onde esta parasitose é endêmica. O objetivo deste estudo foi verificar se estava havendo, de fato, desaparecimento desta patologia ou se este número decrescente refletia apenas diminuição marcante de casos graves de esquistossomose mansônica acompanhados neste Hospital. Para isso foram comparadas as prevalências de glomerulopatia em hepatosplênicos esquistossomóticos autopsiados no Hospital Universitário Prof. Edgard Santos em duas décadas: de 1960-70, antes da intervenção terapêutica nas áreas endêmicas de esquistossomose com oxamniquine, e de 19801990, após a adoção desta intervenção. Houve grande redução no número de doentes com hepatosplenomegalia esquistossomótica autopsiados no Hospital Universitário Prof. Edgard Santos quando comparadas a década antes (140 autópsias) e depois (31 autópsias) do tratamento com oxamniquine. A prevalência de glomerulopatia, entretanto, persistiu a mesma (11,4\% comparada com 12,9\%, respectivamente). A conclusão é que a redução do achado de glomerulopatia esquistossomótica em nossos dias reflete apenas a redução das formas graves da parasitose após a intervenção terapêutica nas áreas endêmicas.

Palavras-chaves: Esquistossomose mansônica. Glomerulopatia. Hepatosplenomegalia esquistossomótica. Envolvimento renal. Forma Hepatosplênica.
\end{abstract}

Já se sabe, de há muitos anos, que 10-15\% dos doentes com hepatoesplenomegalia esquistossomótica apresentam uma glomerulopatia que se manifesta, na maioria dos casos, por uma síndrome nefrótica4. Trata-se de uma glomerulonefrite, com depósito de antígeno específico do Schistosoma mansoni nos capilares glomerulares, que, quando se manifesta clinicamente, apresenta evolução progressiva, conduzindo o doente ao estádio final da doença renal, exigindo tratamento dialítico ou transplante renal5. Infelizmente, este acometimento renal não responde ao tratamento específico da parasitose, assim como, também, ao uso de corticóide ou ciclofosfamida3. Nos últimos 10 anos reduziu-se muito o número de doentes com glomerulopatia esquistossomótica admitidos em nosso Hospital Universitário. Este fato está

Departamento de Medicina da Universidade Federal da Bahia, Salvador, BA.

Endereço para correspondência: Prof. Heonir Rocha. Hospital Universitário Prof. Edgard Santos. R. João das Botas s/n ${ }^{\circ}$, Canela, 40110-160 Salvador, BA. Fax: (071) 245-7110 Recebido para publicação em 07/01/97. ocorrendo alguns anos depois do tratamento em massa levado a efeito nas áreas endêmicas com oxamniquine, feito pelo Ministério da Saúde, visando o controle desta parasitose. O impacto desta intervenção terapêutica foi evidente. Reduziu-se a intensidade de infestação de muitos doentes, com reversão de hepatoesplenomegalia em alguns deles em zona endêmica ${ }^{2}$. É racional resumir-se que se a lesão glomerular se relaciona com a intensidade da parasitose e o tipo e duração do processo, a mudança nestes parâmetros em muitos doentes tenha reduzido o número de casos com glomerulopatia.

Para analisar este problema resolvemos comparar o número de casos graves de esquistossomose mansônica (com hepatoesplenomegalia) falecidos e autopsiados no Hospital Universitário Professor Edgar Santos (HUPES) no período de 1960-1970 (período anterior à intervenção terapêutica com oxamniquine) com a década de 1980-1990 após a intervenção terapêutica. Todos os doentes autopsiados nestes dois períodos de 10 anos, portadores de hepatoesplenomegalia esquistossomótica tiveram os seus prontuários 
Comunicação. Correia EIS, Martinelli RP, Rocha H. Está desaparecendo a glomerulopatia da esquistossomose mansônica? Revista da Sociedade Brasileira de Medicina Tropical 30:341-343, jul-ago, 1997.

revistos e dados de identificação, características macroscópicas do fígado e do baço, assim como achados de autópsia referentes às condições histológicas do fígado, baço e rins, foram devidamente catalogados.

A Figura 1 nos mostra que houve um grande decréscimo de casos de esquistossomose mansônica hepatoesplênica falecidos no Hospital Universitário na última década analisada, quando comparada à década de 1960-1970.
Entretanto, a prevalência de glomerulopatia quando comparadas estas duas décadas estudadas (60 a 70 e 80 a 90) mostra os mesmos índices de envolvimento glomerular (Tabela 1 ), praticamente iguais aos anteriormente relatados1. Vale destacar que o HUPES continua recebendo doentes das mesmas áreas endêmicas de esquistossomose mansônica, sem restrições ao seu atendimento até o presente momento.

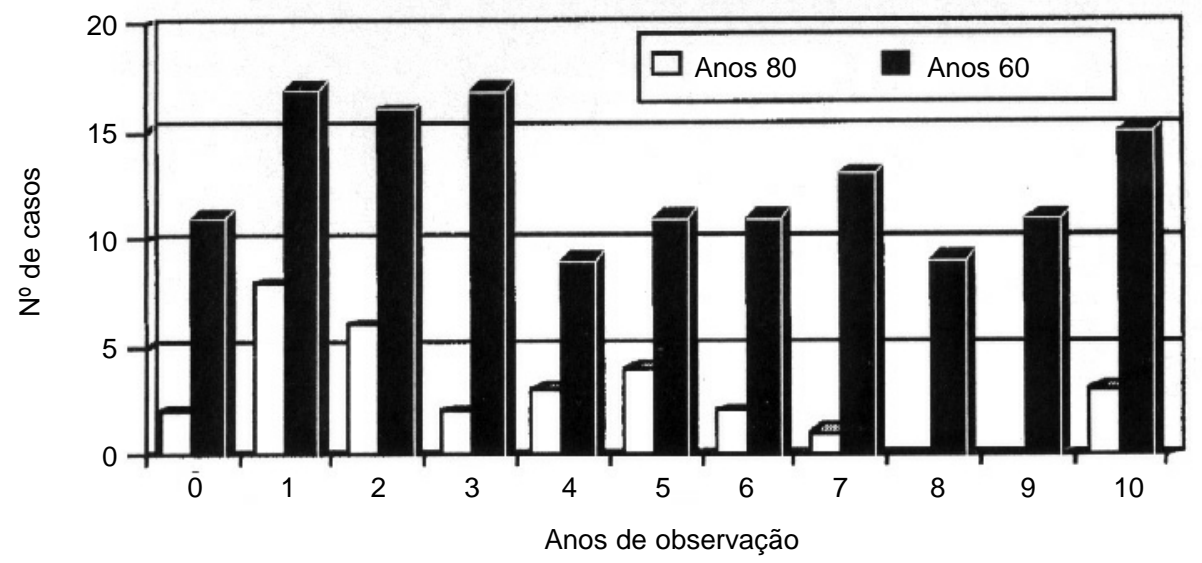

Figura 1 - Comparação entre o número de casos de esquistossomose bepato-esplênica autopsiados no HUPES nas décadas de 60 e 80 .

Tabela 1 - Prevalência de glomerulonefrite em pacientes com esquistossomose mansônica hepatoesplência autopsiados no HUPES nas décadas de 1960-1970 e 1980-1990.

\begin{tabular}{lccc}
\hline Década & $\begin{array}{c}\text { Número de } \\
\text { autópsias }\end{array}$ & $\begin{array}{c}\text { Número de casos } \\
\text { com glomerulonefrite }\end{array}$ & $\%$ \\
\hline $1960-1970$ & 140 & 16 & 11,4 \\
$1980-1990$ & 31 & 4 & 12,9 \\
\hline
\end{tabular}

\section{SUMMARY}

Hepatosplenic form of S. mansoni infection may be accompanied by a glomerulopathy in 12-15\% of cases, manifested in the majority by a nephrotic. This type of renal involvement is becoming a rare occurrence in our University Hospital (Hospital Universitário Prof. Edgard Santos) a typical general hospital in an endemic state for this parasitic disease. To investigate this fact, autopsied cases with patients with hepatosplenic form of schistosomiasis mansoni during two decades in our Hospital - 196070, (before a therapeutic intervention in endemic areas with oxamniquine) and 1980-1990 (after the intervention) were compared in reference to number of cases and the finding of glomerulonephritis by bistological examination. Even though there was a strinking decrease in number of patients with advanced forms of this disease (140 as compared to 31 autopsies in these two decades), the prevalence of glomerulonephritis diagnosed was 11.4 (16 cases) in the first and 12.9 (4 cases) in the second. As there was no change in pattern of attendance in this Hospital, the drastic decrease in number of severe forms of this parasitic infection following massive therapy of the endemic population with oxamniquine in the most likely explanation not only for the decrease in number of hepatosplenic cases but, also, and as a consequence, the scarcity of cases of the schistosomal glomerulopathy observed.

Key-words: Schistosomiasis mansoni. Glomerulopathy. Schistosomal glomerulopathy. Hepatosplenic form. 


\section{REFERÊNCIAS BIBLIOGRÁFICAS}

1. Andrade ZA, Rocha H. Schistosomal Glomerulopathy. Kidney International 16:2329,1979 .

2. Bina JC. O tratamento específico como arma no controle da esquistossomose. Memórias do Instituto Oswaldo Cruz 87:195-202, 1992.

3. Martinelli R, Noblat ACB, Brito E, Rocha $H$. Schistosoma mansoni-induced mesangiocapillary glomerulonephrites: Influence of therapy. Kidney International 35:1227-1233, 1989.
4. Queiroz FP, Brito E, Martinelli R, Rocha H. Nephrotic syndrome in patients with Schistosoma mansoni infections. The American Journal of Tropical Medicine and Hygiene 22:622-628, 1973.

5. Sobh MA, Moustafa FE, El-Houssein F, Bosta MT, Deelder AM, Ghoniem MA. Schistosomal specific nephropathy leading to end-stage renal failure. Kidney International 31:1006-1011, 1987. 